\title{
Exosomes from adipose-derived mesenchymal stem cells prevent cardiomyocyte apoptosis induced by oxidative stress
}

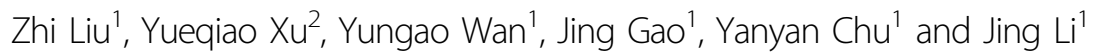

\begin{abstract}
Exosomes from bone marrow stem cells or cardiac progenitor cells can reduce apoptosis in myocardial cells after ischemia and reperfusion injury. However, there is little known about the effects of exosomes from adipose-derived stem cells (ADSCs), which are more abundant and have a lower risk of side effects. The aim of this study was to characterize exosomes from ADSCs and evaluate their cardioprotective actions against ischemia reperfusion injury. The exosomes were isolated from ADSCs and analyzed by protein marker expression, transmission electron microscopy, and nanoparticle tracking analysis. The ADSC-exosomes were then used for ex vivo investigation of the cardioprotective effects on cardiomyocytes after exposure to oxidative stress. Exosomes from ADSCs exhibited a diameter of $150 \mathrm{~nm}$ and expressed the marker proteins, CD9 and CD29. ADSC-exosomes had no effect on proliferation of untreated cardiomyocytes. In contrast, ADSC-derived exosomes reduced apoptosis in myocardial cells subjected to oxidative stress. This study confirms that exosomes originating from ADSCs can protect cardiomyocytes from oxidative stress.
\end{abstract}

\section{Introduction}

Acute reperfusion is the best treatment for acute myocardial infarction (AMI). However, ischemic reperfusion injury induces oxidative stress and inflammation, leading to myocardial cell apoptosis, myocardial remodeling, and decreased cardiac function ${ }^{1,2}$. Currently, there is no effective clinical therapy for ischemia reperfusion injury ${ }^{3}$. Cell therapies were developed in the hope that stem cells could proliferate and differentiate into new myocardial cells to improve myocardial function after myocardial infarction ${ }^{3,4}$. However, $<1 \%$ of stem cells reach the site of injury and differentiate in cariomyocytes ${ }^{5}$.

Correspondence: Jing Li (shpxbb@sina.com)

'Department of Cardiology, Xuanwu Hospital, Capital Medical University, Beijing, China

2Department of Neurosurgery, Xuanwu Hospital, Capital Medical University, Beijing, China

Edited by I. Harris
Exosomes may mediate much of the therapeutic benefit of stem cells ${ }^{6-9}$. Exosomes are lipid bilayer membrane vesicles formed by stem cells through the process of endocytosis, fusion, and efflux. Exosomes can alter the behavior of recipient cells and improve the cardiac microenvironment after AMI. Exosomes can ferry microribonucleic acid (miRNA) and proteins, facilitating intercellular communication through target cell internalization, receptor-ligand interactions, or lipid-membrane fusion ${ }^{10,11}$. Exosomes of various mesenchymal stem cells (MSCs) have been shown to restore bioenergetics, alleviate inflammatory and oxidative stress, and improve vascular generation ${ }^{12-16}$. As shown in animal and human models of myocardial ischemia reperfusion injury, exosomes can inhibit myocardial apoptosis, narrow the scope of myocardial infarction, preserve left ventricular geometry, and improve cardiac function ${ }^{17-21}$. However, exosomes secreted by adipose-derived stem cells (ADSCs) have not been fully characterized.

\section{(c) The Author(s) 2019}

(c) Open Access This article is licensed under a Creative Commons Attribution 4.0 International License, which permits use, sharing, adaptation, distribution and reproduction cc) in any medium or format, as long as you give appropriate credit to the original author(s) and the source, provide a link to the Creative Commons license, and indicate if changes were made. The images or other third party material in this article are included in the article's Creative Commons license, unless indicated otherwise in a credit line to the material. If material is not included in the article's Creative Commons license and your intended use is not permitted by statutory regulation or exceeds the permitted use, you will need to obtain permission directly from the copyright holder. To view a copy of this license, visit http://creativecommons.org/licenses/by/4.0/. 
We hypothesized that endogenous exosomes communicate signals to the heart to protect it against ischemia and reperfusion injury. Oxidative stress is crucial to the development of ischemia-reperfusion injury. Oxidative stress activates reactive oxygen species (ROS) signaling, leading to cell death. In many ischemia-reperfusion injury studies, cardiomyocytes were exposed to $\mathrm{H}_{2} \mathrm{O}_{2}{ }^{22,23}$. $\mathrm{H}_{2} \mathrm{O}_{2}$-induced oxidative stress can reduce viability and increase apoptosis of cardiomyocytes. The aim of our study was to examine the effects of exosomes on cardiomyocytes under oxidative stress. We purified, characterized, and quantified exosomes from ADSCs of mice. Our results show that exosomes from ADSCs protect against oxidative stress injury in vitro.

\section{Materials and methods}

\section{Cell culture}

We purchased mouse ADSCs from Cyagen Biosciences Inc. (cat. MUBMD-01001). ADSCs were routinely cultured in DMEM/F12 (1:1) medium containing $100 \mathrm{U} / \mathrm{mL}$ penicillin, $100 \mu \mathrm{g} / \mathrm{mL}$ streptomycin, and $10 \%$ fetal bovine serum (FBS). The M6200 mouse cardiomyocyte cell line (MCM) was obtained from the Chinese Science Academy Cell Bank (Shanghai, China). MCM cells were cultured in high-glucose DMEM medium with $100 \mu \mathrm{g} / \mathrm{mL}$ streptomycin, $100 \mu \mathrm{g} / \mathrm{mL}$ penicillin (Gibco, NY, USA), and $10 \%$ FBS in a humidified incubator at $37{ }^{\circ} \mathrm{C}$ with $5 \% \mathrm{CO}_{2}$.

\section{Identification of ADSCs}

The ADSCs from passage 3 were digested with $0.25 \%$ trypsin, and $1 \times 10^{6}$ cells were incubated with the following antibodies: Anti-Human CD34 FITC (1:1000; eBioscience), Anti-Human CD29 APC (1:1000; eBioscience), and FITC Mouse Anti-Human CD44 (1:1000; BD Pharmingen). Cell purity was determined by surface marker detection using flow cytometry ${ }^{24}$.

\section{CCK-8 assay for growth curve of ADSCs and proliferation}

The ADSC suspension was collected and added to 96well plates, $100 \mu \mathrm{L}$ per well. The culture plates were placed in a $37^{\circ} \mathrm{C}$ incubator and three wells were chosen randomly at $0,2,4,6$, and 8 days. The cells in the selected wells were incubated with $10 \mu \mathrm{L}$ of Counting Kit-8 (CCK-8) for an additional $1 \mathrm{~h}$. The optical density (OD) of each well at a wavelength of $450 \mathrm{~nm}$ was measured with a microplate reader (Bio-Rad, USA) to generate a cell growth curve. Each test was performed in triplicate.

\section{Flow-cytometric analysis of apoptosis}

The effect of ADSCs and exosomes on cell apoptosis was determined using an Annexin V-FITC Apoptosis Detection Kit (Beyotime) and flow cytometry. Co-culture experiments were performed using transwell chamber inserts with $0.4 \mu \mathrm{m}$ pores. MCM cells were seeded in the bottom chambers and ADSCs were seeded in the top chambers. After $200 \mu \mathrm{M} \mathrm{H}_{2} \mathrm{O}_{2}$ treatment for $4 \mathrm{~h}, 5 \times 10^{4}$ MCM cells were suspended in $195 \mu \mathrm{l}$ Annexin V-FITCbinding buffer. MCM cells were co-cultured with ADSCs or not, and then incubated for $10 \mathrm{~min}$ at room temperature in the dark after the addition of $5 \mu$ Annexin V-FITC and $5 \mu \mathrm{l}$ PI staining solution. Annexin V-FITC binding and PI staining were detected using flow cytometry and analyzed with FACSDiva (Becton-Dickinson) software. The experiments were performed independently three times $^{25}$.

\section{Exosome purification}

Exosomes secreted by ADSCs were purified from conditioned medium as described previously ${ }^{26}$. Briefly, $10 \mathrm{~mL}$ of culture medium (ADSCs) with 10\% exosome-depleted FBS was added to ADSC cell cultures in $10 \mathrm{~cm}$ dishes. After $24 \mathrm{~h}$, medium was centrifuged at 1000 RPM for $10 \mathrm{~min}$ and the supernatant was passed through $0.22 \mu \mathrm{m}$ filters to remove dead cells and debris. The high purity exosomes were extracted according to the MagCapture ${ }^{\mathrm{TM}}$ Exosome Isolation Kit PS (Wako, cat. 293-77601). Tim4 protein solidified magnetic beads were used to bind phosphatidyl serine (PS) on the surface of extracellular vesicles in the presence of metal ions, then neutral elution buffer containing EDTA was used to elute the exosome. By using the PS affinity method, isolation of exosomes with high purity and integrity was achieved. The exosome fraction protein content was assessed by the bicinchoninic acid (BCA) assay. We measured the exosome particle size (diameter) and concentration using nanoparticle tracking analysis (NTA).

\section{Electron microscopy}

For transmission electron microscopy (TEM), $10 \mu \mathrm{l}$ of PBS containing exosomes was placed on formvar carboncoated 200-mesh copper electron microscopy grids and incubated for $1 \mathrm{~min}$ at room temperature ${ }^{21}$. For negative staining, $3 \%(\mathrm{w} / \mathrm{v})$ aqueous phosphotungstic acid ( $\mathrm{pH} 6.8)$ was applied onto the grid immediately after water removal and then removed with filter paper after $30 \mathrm{~s}$. The grid was washed with double-distilled water and allowed to semidry at room temperature before being imaged by TEM.

\section{Western blotting}

Exosomal protein content was measured using a BCA assay. Total protein $(40 \mu \mathrm{g})$ was electrophoresed using $10 \%$ SDS-PAGE, and transferred to PVDF membranes (Millipore, USA). Membranes were blocked for $1 \mathrm{~h}$ at RT with $5 \%$ non-fat milk. Then membranes were incubated overnight at $4{ }^{\circ} \mathrm{C}$ with the primary antibody (rabbit antiCD29, 1:1000, Proteintech or mouse anti-CD63, 1:1000, Abcam) diluted in TBST with 5\% BSA. Membranes were washed with TBST, followed by incubation for $1 \mathrm{~h}$ at 
room temperature with either horseradish-peroxidase (HRP)-conjugated goat anti-rabbit secondary antibodies or HRP-conjugated goat anti-mouse (1:1000, Beyotime). The bands were visualized using ECL detection.

\section{Exosome labeling with PKH26}

Purified exosomes derived from ADSCs were labeled using PKH26 red fluorescent labeling kits (Sigma-Aldrich) according to the manufacturer's instructions. The excess dye was removed by adding $1 \%$ BSA solution. The samples were transferred to cell culture media. Exosomes labeled with PKH26 were incubated with the MCM cells for $0,4,8$, and $24 \mathrm{~h}$. The exosomes were removed from the MCM cells by washing the cells three times with PBS. The MCM cells were then incubated with $4 \%$ paraformaldehyde solution for $15 \mathrm{~min}$, followed by three more washes. The washed membrane was mounted on a glass slide with mounting medium containing DAPI. The slides were analyzed using confocal microscopy.

\section{Statistical analysis}

Data are expressed as mean \pm SD and analyzed with SPSS 17.0 software. A $t$-test was used to evaluate the differences among groups. A value of $P<0.05$ was considered to be statistically significant.

\section{Results}

\section{Phenotypic characterization and anti-apoptotic effects of} ADSCs

ADSCs were cultured to passage 3 . Phenotypic analysis via flow cytometry demonstrated that the ADSCs were positive for the MSC markers, CD29 and CD44, and negative for CD34 (Fig. 1a). Growth curves were generated to examine the proliferation of ADSCs. The growth curves for passages, $\mathrm{P} 0, \mathrm{P} 2, \mathrm{P} 4, \mathrm{P} 6$, and $\mathrm{P} 8$, were typically sigmoidal (Fig. 1b).

To assess the effects of ADSCs on cardiomyocytes, MCM cells were co-cultured with ADSCs for $24 \mathrm{~h}$ and then subjected to acute $\mathrm{H}_{2} \mathrm{O}_{2}$ oxidative stress $(4 \mathrm{~h})$.

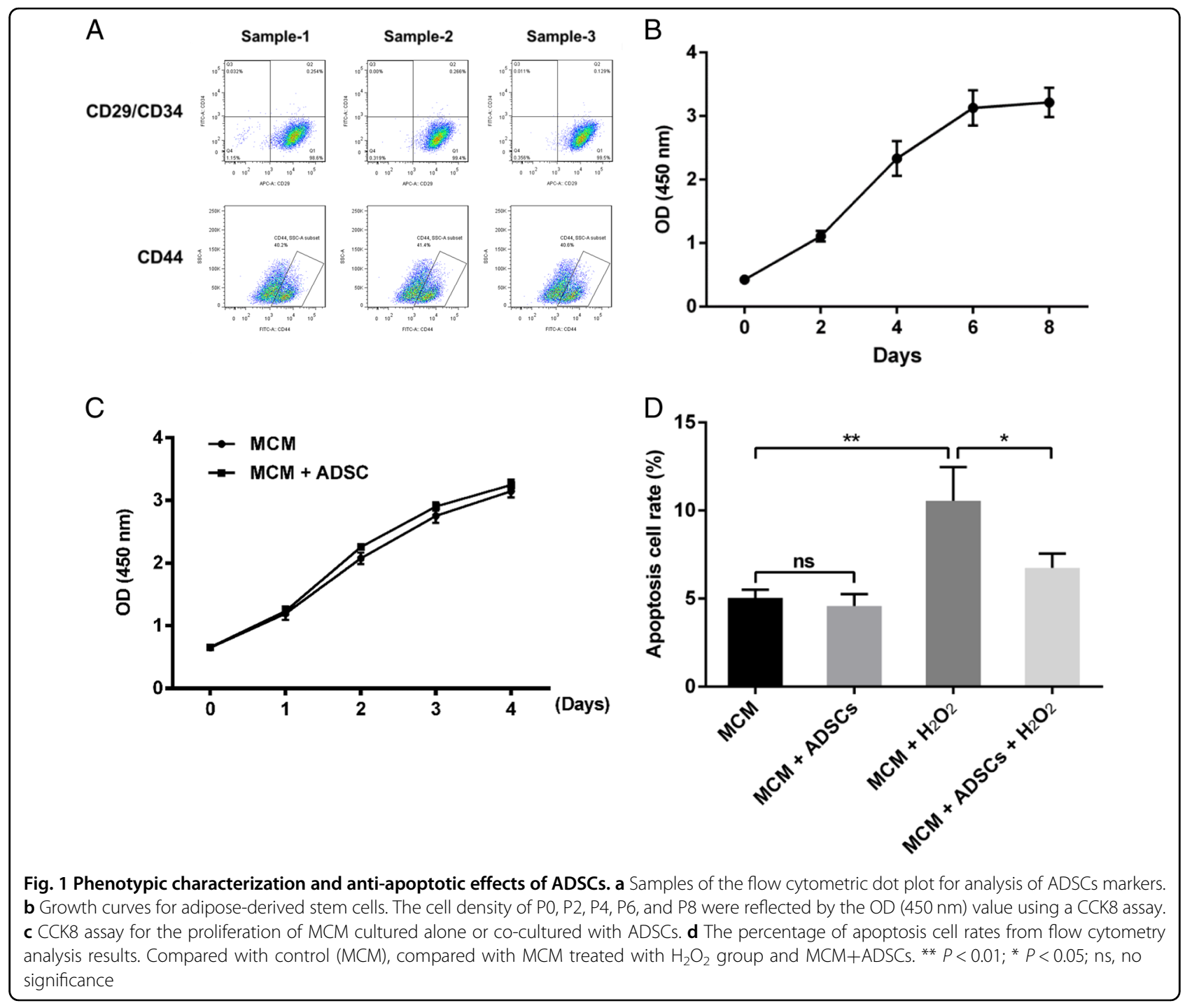


Co-culture with ADSCs resulted in almost no variation in the proliferation of untreated MCM cells (Fig. 1c). As shown in Fig. 1d, the rate of apoptosis for MCM cells was significantly increased after $\mathrm{H}_{2} \mathrm{O}_{2}$ treatment compared to untreated control cells, and ADSCs effectively suppressed this apoptosis in MCM cells.

\section{Characterization of ADSC-exosomes}

Exosomes were readily detectable in media from ADSCs. Morphological analysis of the ADSC-exosomes using electron micrography demonstrated grape-like nanoparticle exosomes (Fig. 2a). The size of exosomes structures was determined using the nanoparticle tracking analyzer for hydrodynamic particle size (Fig. 2b). The pellets consisted of particles with an average size of 150 $\mathrm{nm}$ in diameter, consistent with the characteristic size range of exosomes (Fig. 2b). Western blot analysis of ADSC-exosomes revealed the presence of exosome markers CD63 and CD29 (Fig. 2c). FACS analysis demonstrate that markers CD29 and CD63 are expressed on the surface of the ADSCs (Fig. 2d).

\section{Exosome labeling and uptake by MCM cells}

To determine whether ADSC-exosomes can be efficiently taken up by cardiomyocytes in vitro, we labeled ADSC-exosomes with $\mathrm{PKH} 26$, a fluorescent cell linker compound that is incorporated into the cell membrane by selective partitioning. The nuclei (blue) were counterstained with DAPI. The labeled exosomes were then incubated with MCM cells, which were subsequently examined for fluorescence at varying time points. Our results show that the PKH26-labeled exosomes were taken up by MCM cells within $4 \mathrm{~h}$ after the exosomes were added to the culture medium. Red fluorescence signals were detected in the MCM cells over time (Fig. 3). By $24 \mathrm{~h}$, nearly every MCM cell exhibited red fluorescence. These finding demonstrate that ADSC-exosomes are readily taken up by MCM cells. Thus, exosomes can be used therapeutically to modulate cardiomyocyte function.

\section{Anti-apoptotic effects of ADSC-exosomes on MCM cells under oxidative stress}

In order to determine the effects of exosomes on oxidative stress-induced apoptosis in cardiomyocytes, MCM cells were co-cultured with ADSCs, and/or ADSCexosomes for $24 \mathrm{~h}$. Co-cultures were then treated with 0 or $200 \mu \mathrm{M} \mathrm{H}_{2} \mathrm{O}_{2}$ for $4 \mathrm{~h}$. We measured apoptosis rates in six groups of MCM cells, as shown in Fig. 4. The apoptosis rates were similar among the exosomes, ADSCs, and all co-cultures indicating that exosomes and ADSCs did not alter apoptosis under normal conditions (Fig. 4). The number of apoptotic cells was significantly increased in $\mathrm{H}_{2} \mathrm{O}_{2}$-treated MCM cells. Co-culture with ADSC- exosomes significantly suppressed $\mathrm{H}_{2} \mathrm{O}_{2}$-induced apoptosis $(P<0.01)$. These results indicate that ADSCexosomes protect MCM from oxidative stress.

\section{Discussion}

Previous evidence suggests that exosomes from various stem cells can stimulate regeneration and enhance myocardial function. The present study demonstrates that exosomes from ADSCs decrease oxidative stress-induced apoptosis of myocardial cells. Exosome treatment may restore bioenergetics by complementing key enzymes in the oxidative phosphorylation pathway that were lost during myocardial ischemic reperfusion injury. Exosomes can increase levels of adenosine triphosphate (ATP), reduced nicotinamide adenine dinucleotide (NADH), phosphorylated-Akt, and phosphorylated-GSK-3 $\beta$, and reduce phosphorylated-c-JNK in hearts subjected to ischemic/reperfusion ${ }^{12}$.

Transfer of RNA and DNA through exosomes has emerged as a crucial mechanism by which exosomes can elicit cardioprotection. Genetic exchange can induce gene changes in nearby cells ${ }^{27,28}$. For example, miRNAs can directly regulate the stability of other RNAs and participate in transcriptional regulation of many genes. MiRNAs control important pathological outcomes in myocardial infarction, including the inhibition of myocardial cell apoptosis. MiR-22, which is enriched in MSCs following ischemic preconditioning, has an antiapoptotic effect mediated by direct targeting of methyl CpG binding protein $2^{29}$. MSC overexpression of miR-221 significantly enhances cardioprotection by reducing the expression of p53-upregulated modulator of apoptosis (PUMA) ${ }^{30}$. After AMI, CD34 ${ }^{+}$cells release exosomes enriched with miRNA-126, which promotes angiogenesis ${ }^{31,32}$.

Protective functions of exosomes have also been attributed to heat shock proteins (HSPs). HSPs can repair ion channels, restore redox balance, interact with nitric oxideinduced protection, inhibit proinflammatory cytokines, and prevent apoptosis pathway activation ${ }^{33}$. HSPs are intracellular chaperones important for correct protein homeostasis. Specifically Hsp70 and Hsp27 are capable of protection against irreversible injuries associated with ischemia reperfusion $^{34-36}$. Hsp70 is secreted from cells by exosomes, and protects against oxidative stress and apoptosis; Hsp70 also maintains sarcomeric structure ${ }^{35,37,38}$. Vicencio showed that exosomal Hsp70 activates the downstream pathway of tolllike receptor (TLR) 4, leading to phosphorylation of Hsp27 ${ }^{9}$. Elevated levels of Hsp27 participate in cardioprotection by maintaining the integrity of microtubules and actin cytoskeleton, and protecting the endothelium from ischemia ${ }^{39,40}$. Hsp27 can also act as an endogenous cytoprotective stress response protein, eliciting cardioprotection after ischemic injury via its role as a molecular chaperone ${ }^{41}$. Hsp27 plays a role as a downstream effector of p38 MAPK during 

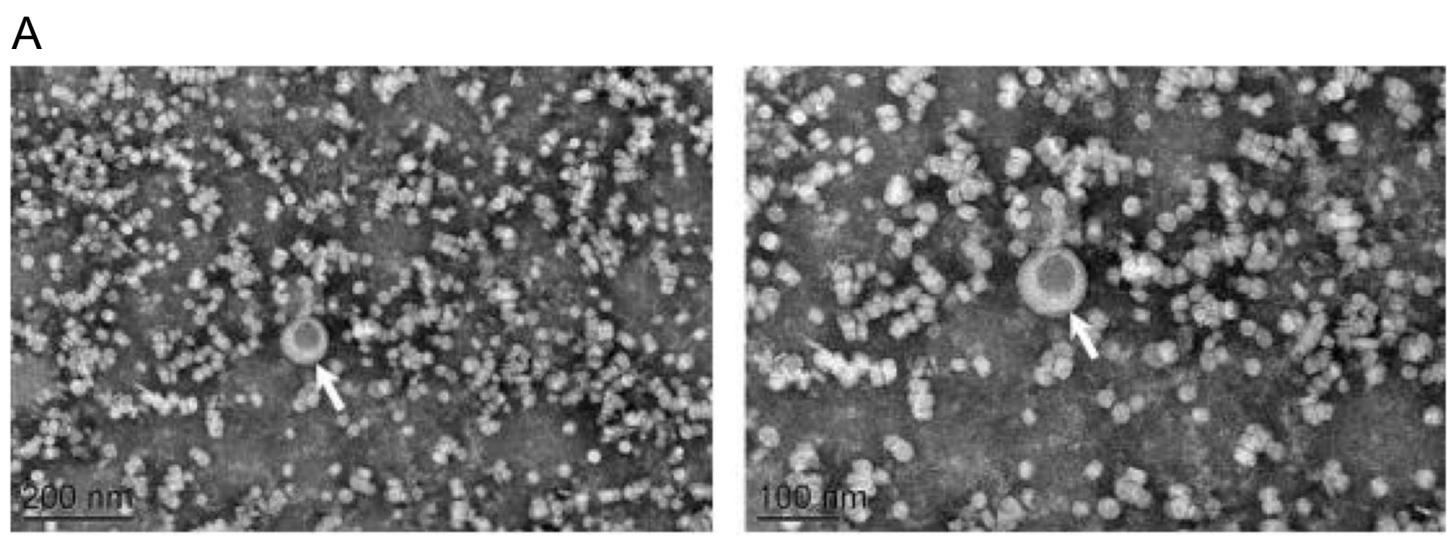

B

C
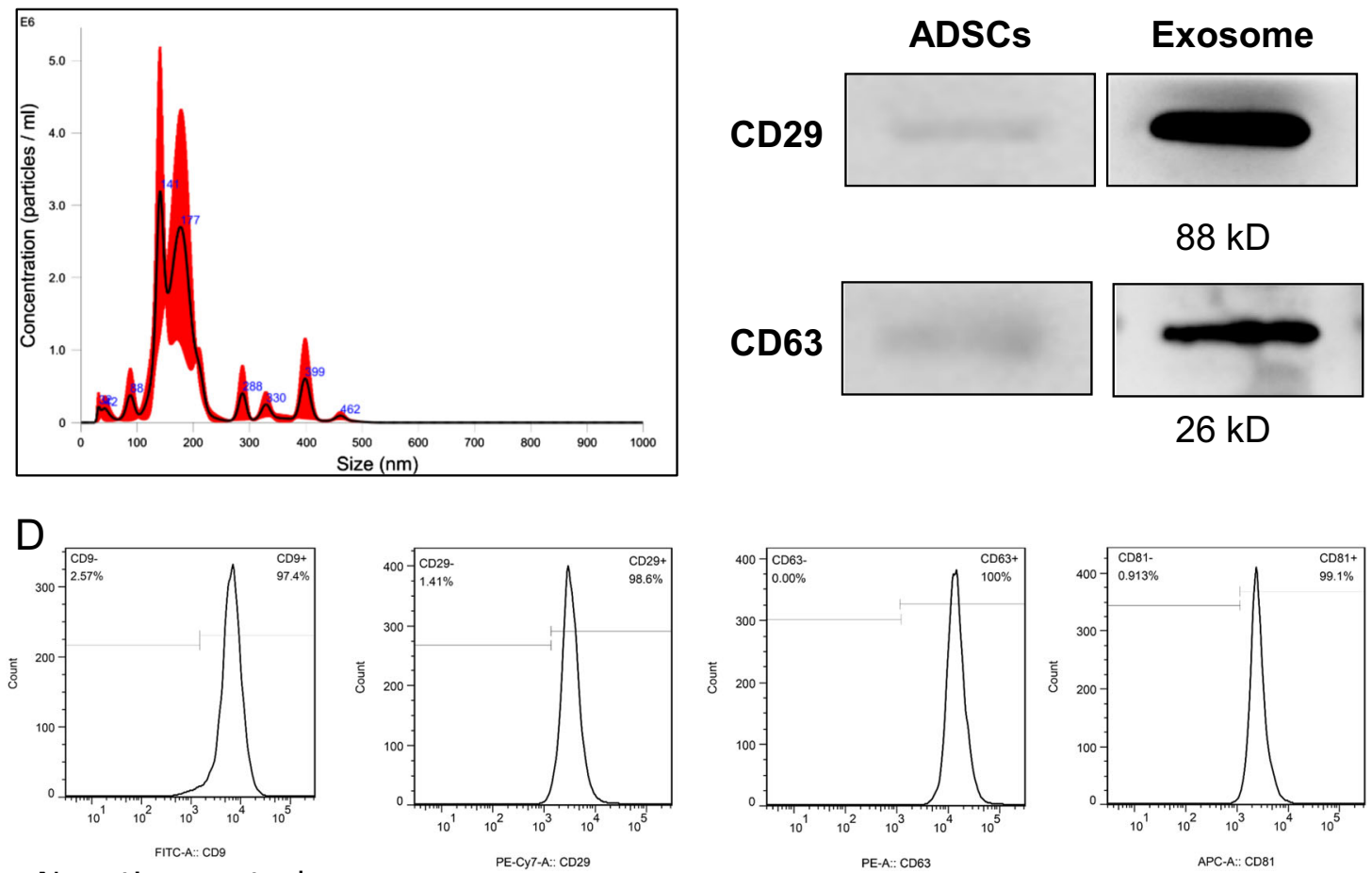

Negative controls
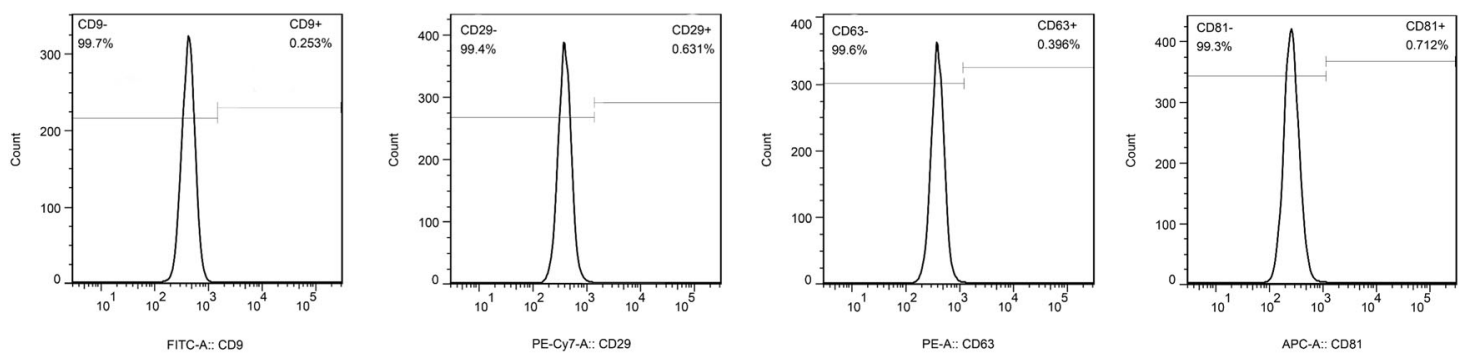

Fig. 2 Characterization of ADSC-exosomes. a Electron micrograph image of ADSC-derived exosomes (arrow indicates exosomes). The image shows a mass of round-shaped vesicles. Scale bar $=200 \mathrm{~nm}$. b Particle size distribution in purified pellets consistent with size range of exosomes (average size $150 \mathrm{~nm}$ ) measured by nanoparticle tracking analysis (NTA). c Western blot results demonstrate the expression of CD29 and CD63 in exosomes derived from ADSCs. d FACS analysis of CD29 and CD63 expressed on the surface of ADSCS 


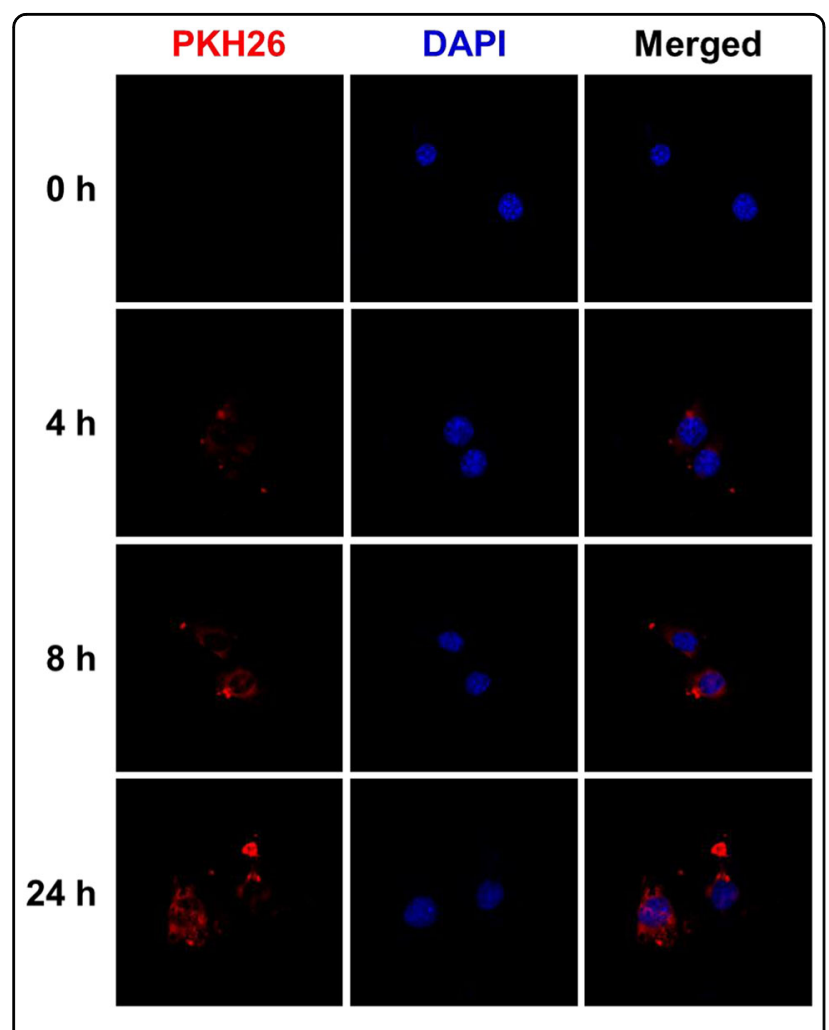

Fig. 3 Time course of cellular uptake of exosomes

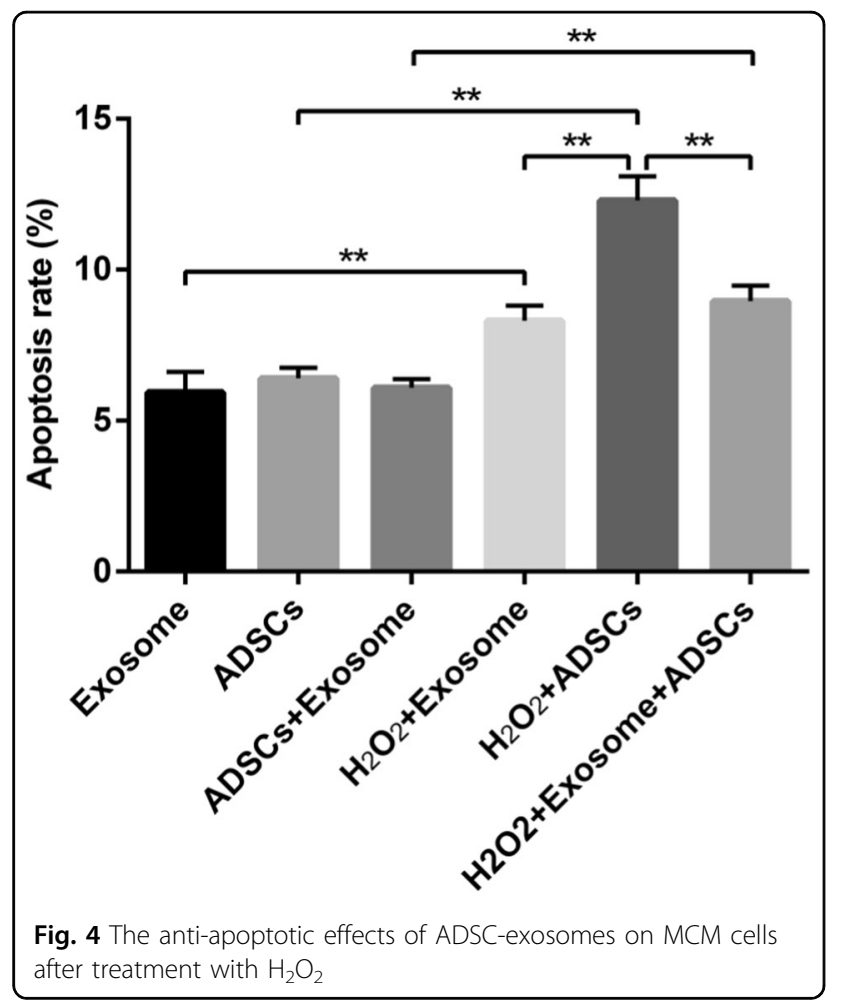

ischemic or $\beta$-adrenergic preconditioning protocols ${ }^{42}$. The Hsp70-TLR4-Hsp27 axis is one of the critical components in exosome-mediated cardioprotection.

Exosomes from ADSCs promote neovascularization and alleviate inflammation and apoptosis after ischemia reperfusion $^{43}$. Treatment of macrophages with ADSCexosomes induces the anti-inflammatory M2 phenotype through transactivation of arginase- 1 by exosome-carried active signal transducer and activator of transcription ${ }^{44}$. Luo demonstrated that exosomes from miR-126overexpressing ADSCs decreased $\mathrm{H} 9 \mathrm{c} 2$ myocardial cell injury by reducing inflammation factor expression during hypoxia induction ${ }^{45}$.

Exosomes may also have a therapeutic effect by reprogramming the microenvironment. Exosome injections significantly reduced apoptosis, in rats that underwent ischemia reperfusion, by enhancing autophagy via the AMPK/mTOR and Akt/mTOR pathways ${ }^{22}$. IL-6, secreted from ADSC-exosomes, stimulated angiogenesis and enhanced recovery after ischemia reperfusion injury by the classic signaling pathway ${ }^{46}$.

In summary, a variety of stem cell exosomes can protect against ischemia injury in the myocardium. This study confirms that exosomes originating from ADSCs can protect cardiomyocytes from oxidative stress.

\section{Study limitations}

It is only an experiment in vitro. Future experiments will be in vivo.

\section{Acknowledgements}

The authors thank Dr. Zhengju Chen for her assistance in experimental design. This work was supported by grant no. Z151100003915095c from Beijing Council of Science and Technology and no. 81470491 from the Natural Science Foundation of China.

\section{Conflict of interest}

The authors declare that they have no conflict of interest.

\section{Publisher's note}

Springer Nature remains neutral with regard to jurisdictional claims in published maps and institutional affiliations.

Received: 21 December 2018 Revised: 29 January 2019 Accepted: 31 January 2019

Published online: 19 March 2019

\section{References}

1. Zhao, Z. Q. Oxidative stress-elicited myocardial apoptosis during reperfusion. Curr. Opin. Pharmacol. 4, 159-165 (2004).

2. Jonathan, T. Is no-no-reflow following PCl in AMI due to distal embolization of plaque and thrombus? Catheter. Cardiovasc. Interv. 82, 210-211 (2013).

3. Derek, J. H. \& Derek, M. Y. Myocardial ischemia-reperfusion injury: a neglected therapeutic target. J. Clin. Invest. 123, 92-100 (2013).

4. Olalla, L. G., Beatriz, P. \& Felipe, P. Induced pluripotent stem cells as a new strategy for cardiac regeneration and disease modeling. J. Mol. Cell. Cardiol. 62 , 43-50 (2013). 
5. Andre, T. \& Atta, B. Stem cell therapy for heart failure: ensuring regenerative proficiency. Trends Cardiovasc. Med. 26, 395-404 (2016).

6. James, J. H. C., Elvira, F. \& Richard, P. H. Developmental origins and lineage descendants of endogenous adult cardiac progenitor cells. Stem Cell Res. 13 592-614 (2014).

7. Kelkar, A. A. et al. Mechanisms contributing to the progression of ischemic and nonischemic dilated cardiomyopathy: possible modulating effects of paracrine activities of stem cells. J. Am. Coll. Cardiol. 66, 2038-2047 (2015).

8. Hall, J. L. \& Hall, J. L. Exosomes decrease infarct size. J. Am. Coll. Cardiol. 65, 1537-1538 (2015)

9. Vicencio, J. M. et al. Plasma exosomes protect the myocardium from ischemiareperfusion injury. J. Am. Coll. Cardiol. 65, 1525-1536 (2015).

10. Belting, M. \& Christianson, H. C. Role of exosomes and microvesicles in hypoxia-associated tumour development and cardiovascular disease. J. Intern. Med. Suppl. 278, 251-263 (2015).

11. Ailawadi, S. et al. Pathologic function and therapeutic potential of exosomes in cardiovascular disease. Biochim. Biophys. Acta 1852, 1-11 (2015).

12. Arslan, F. et al. Mesenchymal stem cell-derived exosomes increase ATP levels, decrease oxidative stress and activate PI3K/Akt pathway to enhance myocardial viability and prevent adverse remodeling after myocardial ischemia/ reperfusion injury. Stem Cell Res. 10, 301-312 (2013).

13. Manole, C. G., Cismaşiu, V., Gherghiceanu, M. \& Popescu, L. M. Experimental acute myocardial infarction: telocytes involvement in neo-angiogenesis. J. Cell. Mol. Med. 15, 2284-2296 (2011).

14. Mercedes, T. \& Clotilde, T. Communication by extracellular vesicles: where we are and where we need to Go. Cell 164, 1226-1232 (2016).

15. Kourembanas, S. Exosomes: vehicles of intercellular signaling, biomarkers, and vectors of cell therapy. Annu. Rev. Physiol. 77, 13-27 (2015).

16. Margaret, A. et al. Exosome-delivered microRNAs modulate the inflammatory response to endotoxin. Nat. Commun. 18, 7321 (2015).

17. Ruenn, C. L., Tian, S. C. \& Sai, K. L. Mesenchymal stem cell exosome: a nove stem cell-based therapy for cardiovascular disease. Regen. Med. 6, 481-492 (2011).

18. Stoorvogel, W. Functional transfer of microRNA by exosomes. Blood 119, 646-648 (2012).

19. Ruenn, C. L. et al. Exosome secreted by MSC reduces myocardial ischemia/ reperfusion injury. Stem Cell Res. 4, 214-222 (2010).

20. Lijuan, C. et al. Cardiac progenitor-derived exosomes protect ischemic myocardium from acute ischemia/reperfusion injury. Biochem. Biophys. Res. Commun. 431, 566-571 (2013).

21. Lucio, B. et al. Extracellular vesicles from human cardiac progenitor cells inhibit cardiomyocyte apoptosis and improve cardiac function after myocardial infarction. Cardiovasc. Res. 103, 530-541 (2014).

22. Liu, L. et al. Exosomes derived from mesenchymal stem cells rescue myocardial ischaemia/reperfusion injury by inducing cardiomyocyte autophagy via AMPK and Akt Pathways. Cell. Physiol. Biochem. 43, 52-68 (2017).

23. Minghua, W. et al. Plasma exosomes induced by remote ischaemic preconditioning attenuate myocardial ischaemia/reperfusion injury by transferring miR-24. Cell Death Dis. 9, 320 (2018).

24. Shuang, Z. et al. Identification and characterization of pig adipose-derived progenitor cells. Can. J. Vet. Res. 80, 309-317 (2016).

25. Yi, D., Fujun, L., Zeng, L., Yanjun, Z. \& Kunlong, M. MiR-429 suppresses the progression and metastasis of osteosarcoma by targeting ZEB1. EXCLI J. 16 618-627 (2017).

26. Changjin, L. et al. Exosomes mediate the cytoprotective action of mesenchymal stromal cells on hypoxia-induced pulmonary hypertension. Circulation 126, 2601-2611 (2012).
27. Lina, $H$. et al. Exosomes in mesenchymal stem cells, a new therapeutic strategy for cardiovascular diseases? Int. J. Biol. Sci. 11, 238-245 (2015).

28. Losordo, D. W. et al. Cardiomyocyte microvesicles contain DNA/RNA and convey biological messages to target cells. PLoS ONE 7, e34653 (2012).

29. Feng, $Y$. et al. Ischemic preconditioning potentiates the protective effect of stem cells through secretion of exosomes by targeting Mecp2 via miR-22. PLOS ONE 9, e88685 (2014).

30. $\mathrm{Yu}, \mathrm{B}$. et al. Cardiomyocyte protection by GATA-4 gene engineered mesenchymal stem cells is partially mediated by translocation of miR-221 in microvesicles. PLOS ONE 8, e73304 (2013).

31. Qiuwang, Z., Ivana, K. \& Michael, J. K. Dysregulation of angiogenesis-related microRNAs in endothelial progenitor cells from patients with coronary artery disease. Biochem. Biophys. Res. Commun. 405, 42-46 (2011).

32. Sahoo, S. et al. Exosomes from human CD34 (+) stem cells mediate their proangiogenic paracrine activity. Circ. Res. 109, 724-728 (2011).

33. Dzaman-Serafin, S., Telatynska-Mieszek, B. \& Ciechanowski, K. Heat shock proteins and their characteristics. Pol. Merkur. Lek. 19, 215-219 (2005).

34. Benjamin, I. J. \& McMillan, D. R. Stress (heat shock) proteins: molecular chaperones in cardiovascular biology and disease. Circ. Res. 83, 117-132 (1998).

35. Martin, J. L., Mestril, R., Hilal-Dandan, R., Brunton, L. L. \& Dillmann, W. H. Small heat shock proteins and protection against ischemic injury in cardiac myocytes. Circulation 96, 4343-4348 (1997).

36. Mymrikov, E. V., Seit-Nebi, A. S. \& Gusev, N. B. Large potentials of small heat shock proteins. Physiol. Rev. 91, 1123-1159 (2011).

37. Heusch, G. Cardioprotection: chances and challenges of its translation to the clinic. Lancet 381, 166-175 (2013).

38. Birnbaum, Y., Hale, S. L. \& Kloner, R. A. Ischemic preconditioning at a distance: reduction of myocardial infarct size by partial reduction of blood supply combined with rapid stimulation of the gastrocnemius muscle in the rabbit. Circulation 96, 1641-1646 (1997).

39. Latchman, D. S. Heat shock proteins and cardiac protection. Cardiovasc. Res. 51, 637-646 (2001)

40. Moghimian, M., Faghihi, M., Karimian, S. M., Imani, A. \& Mobasheri, M. B. Upregulated hsp27 expression in the cardioprotection induced by acute stress and oxytocin in ischemic reperfused hearts of the rat. Chin. J. Physiol. 57, 329-334 (2014).

41. Peart, J. N., Gross, E. R., Headrick, J. P. \& Gross, G. J. Impaired p38 MAPK HSP27 signaling underlies aging-related failure in opioid-mediated cardioprotection. J. Mol. Cell. Cardiol. 42, 972-980 (2007).

42. Marais, E. et al. The temporal relationship between p38 MAPK and HSP27 activation in ischaemic and pharmacological preconditioning. Basic Res. Cardiol. 100, 35-47 (2005).

43. Yun, B. et al. Adipose mesenchymal stem cell-derived exosomes stimulated by hydrogen peroxide enhanced skin flap recovery in ischemia-reperfusion injury. Biochem. Biophys. Res. Commun. 500, 310-317 (2018).

44. Hui, Z. et al. Exosomes from adipose-derived stem cells attenuate adipose inflammation and obesity through polarizing M2 macrophages and beiging in white adipose tissue. Diabetes 67, 235-247 (2018).

45. Luo, Q. et al. Exosomes from MiR-126-overexpressing adscs are therapeutic in relieving acute myocardial ischaemic injury. Cell. Physiol. Biochem. 44 2105-2116 (2017).

46. Pu, C. M. et al. Adipose-derived stem cells protect skin flaps against ischemia/ reperfusion injury via IL-6 expression. J. Invest. Dermatol. 137, 1353-1362 (2017). 